\title{
Long-term Outcome of Adjuvant Chemotherapy with S-1 Consisting of 3-week Administration Followed by 1-week Rest for Stage III Colorectal Cancer
}

\author{
Hidejiro Kawahara ${ }^{1}$, Yuki Hiramoto ${ }^{1}$, Mitsumasa Takeda ${ }^{1}$, Tomo Matusmoto ${ }^{1}$, Takeyuki Misawa ${ }^{1}$ \\ and Katsuhiko Yanaga ${ }^{2}$
}

\author{
Corresponding author: \\ Hidejiro Kawahara, MD, Ph.D. \\ Department of Surgery \\ Kashiwa Hospital, Jikei University \\ School of Medicine, 163-1 \\ Kashiwashita, Kashiwashi, Chiba \\ 277-8567, Japan \\ Tel: +81471641111 Ext. 3421 \\ Fax: +81471633488 \\ E-mail: kawahide@jikei.ac.jp
}

'Department of Surgery, Kashiwa Hospital, Jikei University School of Medicine, Chiba, Japan Department of Surgery, Jikei University School of Medicine, Tokyo, Japan

\section{ABSTRACT}

Background/Aims: The aim of this study is to evaluate long-term outcome of 3-week method (3-week administration followed by 1-week rest) for colorectal cancer as adjuvant chemotherapy with an oral anticancer drug, S-1.

Methods: Between 2008 and 2012, 142 patients with stage III colorectal cancer who underwent curative resection in our hospital and received oral adjuvant chemotherapy with S-1 for six months were enrolled in this study. They were divided into two groups, 3-week method or 4-week method (4-week administration followed 2-week rest).

Results: The six-month completion rate in the 3-week method group was 100\% (49/49) which was significantly better than that in the 4-week method group, $85 \%(79 / 93)$ $(p=0.002)$. In total patients, five-year relapse-free survival rates in the 3-week method group was $89.6 \%$ which was significantly better than that in the 4-week method group, $74.2 \%$ $(p=0.027)$. There were no grade 3 or 4 adverse reactions in both laboratory and clinical findings in the 3-week method group.

Conclusions: The 3-week method of S-1 administration had good feasibility, high accumulated dose in six months and good relapse-free survival rates. The 3-week method with S-1 seems to be a standard adjuvant chemotherapy schedule for colorectal cancer.

Key words: S-1, administration schedule, adjuvant chemotherapy, colorectal cancer

\section{INTRODUCTION}

In Japan, adjuvant chemotherapy after curative resection of colorectal cancer was developed primarily using oral fluorinated pyrimidines such as UFT (combination of uracil and tegafur) (1,2). S-1 (Taiho Pharmaceuticals Co. Ltd., Tokyo, Japan) is an attractive oral fluorinated pyrimidine approved for clinical use since January 1999 in Japan. The agent contains tegafur, 5-chloro-2dihydropyrimidine and potassium oxonate at a molar ratio of 1:0.4:1, based on a biochemical modulation of 5-FU (3). The response rate of S-1 alone exceeded $40 \%$ in two late phase 2 trials for patients with advanced or recurrence gastric cancer $(4,5)$. In Japan, S-1 has been approved as a postoperative adjuvant 
chemotherapeutic agent for colorectal cancer since December 2003. The standard administration schedule of S-1 has been 4-week administration followed by 2-week rest (4-week method). However, the completion rate at one year did not reach $70 \%$ mainly due to adverse reactions $(6,7)$. Compliance of the 4-week method was not satisfactory. Therefore, we tried to start a new administration schedule which was a 3-week administration followed by 1-week rest (3-week method) since 2005, and two study, a pilot study and a prospective randomized trial, were carried out to evaluate feasibility and safety of adjuvant chemotherapy by the 3-week method for colorectal cancer (8). We arrived at the conclusion that adjuvant chemotherapy with the 3-week method using S-1 after curative surgery for colorectal cancer had good feasibility, easily manageable toxicity, high accumulated dose in one year and good compliance (8).

The aim of this study is to evaluate long-term outcome of the 3-week method (3-week administration followed by 1 -week rest) for colorectal cancer as adjuvant chemotherapy with an oral anticancer drug, S-1 as compared to that of the 4 week method.

\section{PATIENTS AND METHODS}

Between 2008 and 2012, 142 patients with stage III colorectal cancer who underwent curative resection in our hospital and received oral adjuvant chemotherapy with S-1 for six months were enrolled in this study. They were divided into two groups, 3-week method or 4-week method (4-week administration followed by 2-week rest). The 3-week method group underwent chemotherapy consisted of six courses of S-1 at $80 \mathrm{mg}$ or $100 \mathrm{mg} /$ body per day according to the body surface area (BSA): BSA $<1.5 \mathrm{~m}^{2}, 80 \mathrm{mg} / \mathrm{day} ;>1.5 \mathrm{~m}^{2}, 100 \mathrm{mg} /$ day. S-1 was administered orally, twice daily after meals for 4 weeks after surgery. While, the 4-week method group underwent chemotherapy consisting of four courses of S-1 at $80 \mathrm{mg}$ or $100 \mathrm{mg} /$ body per day according to BSA: BSA $<1.5 \mathrm{~m}^{2}, 80 \mathrm{mg} /$ day; $>1.5 \mathrm{~m}^{2}$, $100 \mathrm{mg} /$ day. S-1 was administered orally, twice daily after meals for 4 weeks after surgery. Choice of treatment schedule, 3-week method or 4-week method, was based on the preference of the patient's primary physicians.

\section{Treatment schedule}

Physical examinations, routine blood analyses, and serum carcinoembryonic antigen (CEA) measurements were performed every two months after surgery.
Colonoscopy was performed every year after surgery. Computed tomography (CT) was performed every six months or when a patient's serum CEA value was higher than the normal level, $5.0 \mathrm{ng} / \mathrm{ml}$. Positron emission tomography (PET) or PET/CT was not routinely performed but was occasionally employed for patients who had equivocal conventional imaging studies to detect occult metastasis if indicated.

\section{Statistical analysis}

Continuous variables are expressed as the mean and range. The Wilcoxon rank-sum test was used for the comparison of continuous variables, and the chi-square test was used for the comparison of categorical data. Relapse-free survival rates after surgery were examined by the Kaplan-Meier method and log-rank test. A P-value of less than 0.05 indicated significance. All data were analyzed with SPSS version 24.0 (IBM Japan, Ltd, Tokyo, Japan).

\section{RESULTS}

\section{Comparison of all patients' characteristic between the two groups.}

No significant differences were identified in age, gender, tumor site, tumor diameter, pathological type of tumor, depth of tumor invasion, number of lymph node metastasis, or surgical procedure. While, significant difference was found in surgical procedure $(p<0.001)$. The six-month completion rate in the 3-week method group was $100 \%$ (49/49) which was significantly better than that in the 4-week method group, $85 \%$ (79/93) $(p=0.002)$ (table 1).

\section{Comparison of relapse-free survival rates after surgery between the two groups}

In total patients, five-year relapse-free survival rates in the 3-week method group was $89.6 \%$ which was significantly better than that in the 4-week method group, $74.2 \%$ ( $p=0.027$ ) (fig. 1).

\section{Comparison of characteristic of patients with colon cancer between the two groups}

No significant differences were identified in age, gender, tumor site, tumor diameter, pathological type of tumor, depth of tumor invasion, number of lymph node metastasis, or surgical procedure. While, the six-month completion rate in the 3-week method group 
Table 1 - Comparison of characteristic between 3-week and 4-week method

\begin{tabular}{|c|c|c|c|}
\hline Characteristic & 3-week method (n=49) & 4-week method $(n=93)$ & $\mathrm{p}$ value \\
\hline Mean age (range), years & $64.1(35-80)$ & $65.5(31-80)$ & 0.518 \\
\hline $\begin{array}{l}\text { Gender, n }(\%) \\
\text { Male } \\
\text { Female }\end{array}$ & $\begin{array}{l}32(65) \\
17(35)\end{array}$ & $\begin{array}{l}61(66) \\
32(34)\end{array}$ & 0.973 \\
\hline $\begin{array}{l}\text { Tumor site, } \mathrm{n}(\%) \\
\quad \text { Colon } \\
\quad \text { Rectum }\end{array}$ & $\begin{array}{l}30(61) \\
19(39)\end{array}$ & $\begin{array}{l}57(61) \\
36(39)\end{array}$ & 0.994 \\
\hline Mean tumor diameter (rang) $\mathrm{mm}$ & $48.2(10-140)$ & $51.9(12-210)$ & 0.147 \\
\hline $\begin{array}{l}\text { Pathology, } \mathrm{n}(\%) \\
\text { Well differentiated adenocarcinoma } \\
\text { Moderately differentiated adenocarcinoma } \\
\text { Others }\end{array}$ & $\begin{array}{c}10(20) \\
33(67) \\
6(13)\end{array}$ & $\begin{array}{c}23(25) \\
61(66) \\
9(9)\end{array}$ & 0.789 \\
\hline $\begin{array}{c}\text { T number, } \mathrm{n}(\%) \\
\text { T1 } \\
\text { T2 } \\
\text { T3 } \\
\text { T4a } \\
\text { T4b }\end{array}$ & $\begin{array}{c}2(4) \\
6(12) \\
25(51) \\
14(29) \\
2(4)\end{array}$ & $\begin{array}{c}5(5) \\
2(2) \\
56(61) \\
25(27) \\
5(5)\end{array}$ & 0.163 \\
\hline $\begin{array}{l}\text { Number of lymph node metastasis } \\
\quad \leq 3 \\
>3\end{array}$ & $\begin{array}{l}34(69) \\
15(31)\end{array}$ & $\begin{array}{l}70(75) \\
23(25)\end{array}$ & 0.452 \\
\hline $\begin{array}{l}\text { Surgical procedure } \\
\text { Laparoscopic surgery } \\
\text { Open surgery }\end{array}$ & $\begin{array}{l}30(61) \\
19(39)\end{array}$ & $\begin{array}{l}19(20) \\
74(80)\end{array}$ & $<0.001$ \\
\hline $\begin{array}{l}\text { Accomplishment of regimen } \\
\text { Complete } \\
\text { Incomplete }\end{array}$ & $\begin{array}{c}49(100) \\
0(0)\end{array}$ & $\begin{array}{l}79(85) \\
14(15)\end{array}$ & 0.002 \\
\hline
\end{tabular}

was $100 \%$ (30/30) which was significantly better than that in the 4-week method group, 84\% (48/57) $(p=0.025)$ (table 2).

Comparison of relapse-free survival rates after surgery between the two groups.

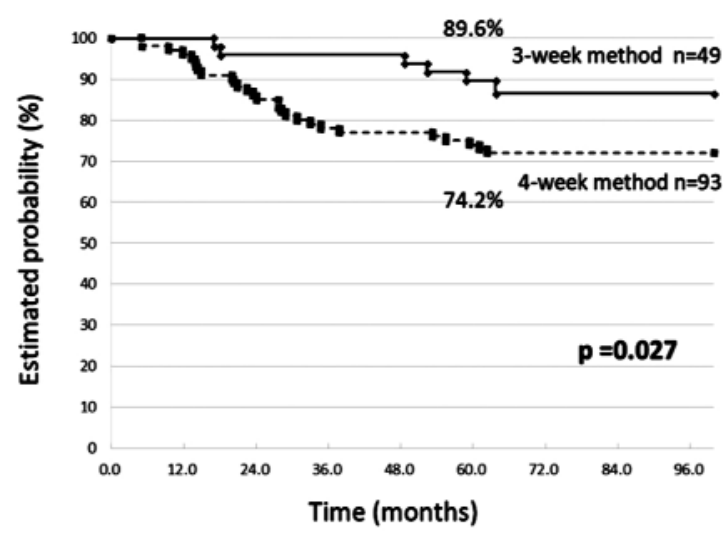

Figure 1 - Comparison of relapse-free survival rates after surgery between the two groups. In total patients, five-year relapse-free survival rates in the 3-week method group was $89.6 \%$ which was significantly better than that in the 4-week method group, $74.2 \%$ $(p=0.027)$
In patients with colon cancer, five-year relapse-free survival rates in the 3-week method group was $86.2 \%$ which was identified no significant difference compared with that in the 4-week method group, 73.7\% ( $p=0.253)$ (fig. 2).

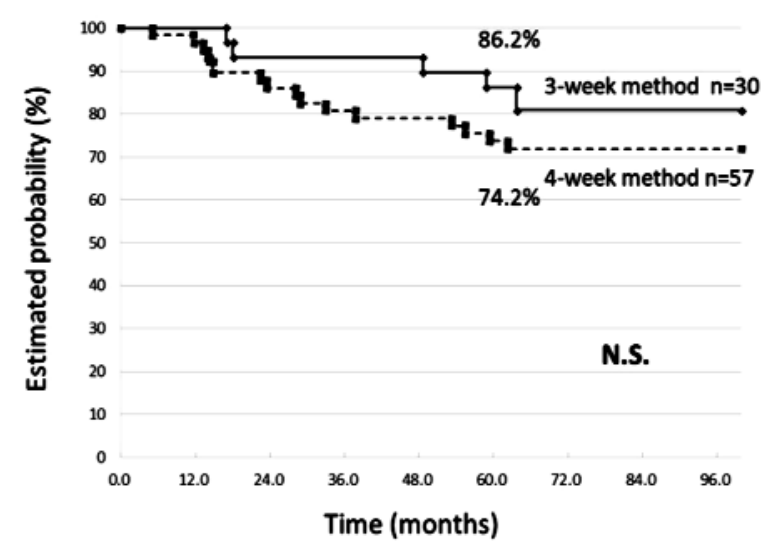

Figure 2 - Comparison of relapse-free survival rates after surgery between the two groups. In patients with colon cancer, five-year relapse-free survival rates in the 3-week method group was $86.2 \%$ which was identified no significant difference compared with that in the 4-week method group, $73.7 \%$ 
Table 2 - Comparison of characteristic between 3-week and 4-week method in colon cancer

\begin{tabular}{|c|c|c|c|}
\hline Characteristic & 3-week method (n=30) & 4-week method ( $n=57)$ & $\mathrm{p}$ value \\
\hline Mean age (range), years & $66.7(36-80)$ & $68.1(44-80)$ & 0.937 \\
\hline Gender, $\mathrm{n}(\%)$ & & & 0.338 \\
\hline Male & $21(70)$ & $34(60)$ & \\
\hline Female & $9(30)$ & $23(40)$ & \\
\hline Mean tumor diameter (rang) $\mathrm{mm}$ & $48.6(10-140)$ & $50.6(14-210)$ & 0.430 \\
\hline Pathology, n (\%) & & & 0.873 \\
\hline Well differentiated adenocarcinoma & $7(23)$ & $16(28)$ & \\
\hline Moderately differentiated adenocarcinoma & $20(67)$ & $35(61)$ & \\
\hline Others & $3(10)$ & $6(11)$ & \\
\hline T number, $\mathrm{n}(\%)$ & & & 0.479 \\
\hline $\mathrm{T} 1$ & $2(7)$ & $4(7)$ & \\
\hline $\mathrm{T} 2$ & $3(10)$ & $1(2)$ & \\
\hline T3 & $15(50)$ & $34(60)$ & \\
\hline $\mathrm{T} 4 \mathrm{a}$ & $9(30)$ & $15(26)$ & \\
\hline $\mathrm{T} 4 \mathrm{~b}$ & $1(3)$ & $3(5)$ & \\
\hline Number of lymph node metastasis & & & 0.757 \\
\hline$\leq 3$ & $22(73)$ & $40(70)$ & \\
\hline$>3$ & $8(27)$ & $17(30)$ & \\
\hline Surgical procedure & & & 0.004 \\
\hline Laparoscopic surgery & $14(47)$ & $10(18)$ & \\
\hline Open surgery & $16(53)$ & $47(82)$ & \\
\hline Accomplishment of regimen & & & 0.025 \\
\hline Complete & $30(100)$ & $48(84)$ & \\
\hline Incomplete & $0(0)$ & $9(16)$ & \\
\hline
\end{tabular}

\section{Comparison of characteristic of patients with rectal cancer between the two groups}

No significant differences were identified in age, gender, tumor site, tumor diameter, pathological type of tumor, depth of tumor invasion, number of lymph node metastasis, or completion rate. While, significant difference was found in surgical procedure $(p<0.001)$. (table 3).

\section{Comparison of relapse-free survival rates after surgery between the two groups}

In patients with rectal cancer, five-year relapse-free survival rates in the 3 -week method group was $94.4 \%$ which was significantly better than that in the 4-week method group, $75.0 \%$ ( $p=0.043$ ) (fig. 3).

\section{DISCUSSION}

Ohtsu et al. (9) reported that S-1 achieves similar responses to the standard regimen of 5-FU plus LV for colorectal cancer and showed the potential of being an alternative to such a combination. The adjuvant chemotherapy after curative resection of colorectal cancer was developed primarily using oral fluorinated pyrimidines in Japan. S-1 has already been a key drug of chemotherapy for colorectal cancer now (10). According to the 2016 guideline, the adjuvant chemotherapy indicates for patients with stage III colorectal cancer for which RO resection has been

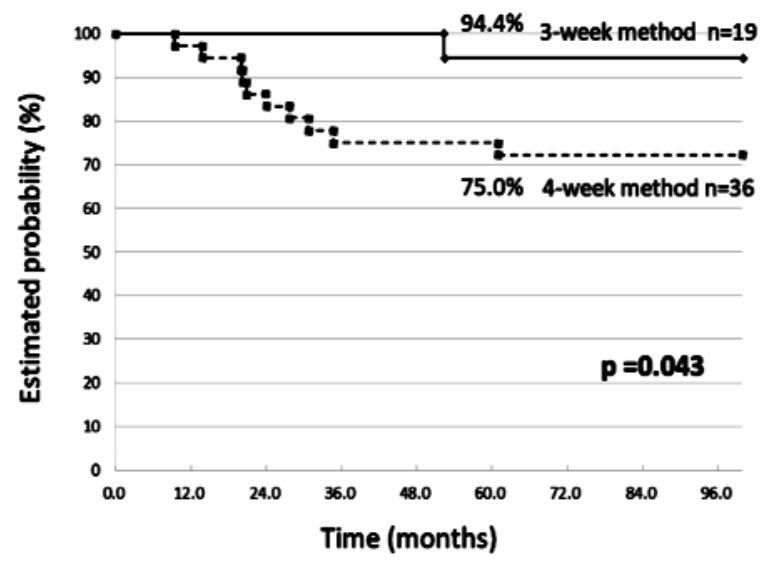

Figure 3 - Comparison of relapse-free survival rates after surgery between the two groups. In patients with rectal cancer, five-year relapse-free survival rates in the 3 -week method group was $94.4 \%$ which was significantly better than that in the 4-week method group, $75.0 \%(p=0.043)$ 
Table 3 - Comparison of characteristic between 3-week and 4-week method for rectal cancer

\begin{tabular}{|c|c|c|c|}
\hline Characteristic & 3-week method $(n=19)$ & 4-week method $(n=36)$ & $p$ value \\
\hline Mean age (range), years & $59.8(35-80)$ & $61.3(31-80)$ & 0.714 \\
\hline Gender, n (\%) & & & 0.192 \\
\hline Male & $11(58)$ & $27(75)$ & \\
\hline Female & $8(42)$ & $9(25)$ & \\
\hline Mean tumor diameter (rang) mm & $47.5(15-100)$ & $54.1(12-108)$ & 0.140 \\
\hline Pathology, n (\%) & & & 0.687 \\
\hline Well differentiated adenocarcinoma & $3(16)$ & $7(20)$ & \\
\hline Moderately differentiated adenocarcinoma & $13(68)$ & $26(72)$ & \\
\hline Others & $3(16)$ & $3(8)$ & \\
\hline T number, $\mathrm{n}(\%)$ & & & 0.465 \\
\hline $\mathrm{T} 1$ & $0(0)$ & $1(3)$ & \\
\hline $\mathrm{T} 2$ & $3(16)$ & $1(3)$ & \\
\hline T3 & $10(53)$ & $22(61)$ & \\
\hline T4a & $5(26)$ & $10(27)$ & \\
\hline $\mathrm{T} 4 \mathrm{~b}$ & $1(5)$ & $2(6)$ & \\
\hline Number of lymph node metastasis & & & 0.094 \\
\hline$\leq 3$ & $12(63)$ & $30(83)$ & \\
\hline$>3$ & $7(37)$ & $6(17)$ & \\
\hline Surgical procedure & & & $<0.001$ \\
\hline Laparoscopic surgery & $16(84)$ & $9(25)$ & \\
\hline Open surgery & $3(16)$ & $27(75)$ & \\
\hline Accomplishment of regimen & & & 0.226 \\
\hline Complete & $19(100)$ & $31(86)$ & \\
\hline Incomplete & $0(0)$ & $5(14)$ & \\
\hline
\end{tabular}

performed. And the recommend administration period is 6 months (10).

The 4 week administration of $\mathrm{S} 1$ followed by a 2 week rest regimen has been established as the standard regimen for $\mathrm{S} 1$ therapy. Results from a post marketing survey on 4,177 patients with advanced recurrent gastric cancer demonstrated that the rate of toxicity for the 4 week / 2 week regimen was $74.3 \%$ and the rate of $\geq$ grade 3 adverse events was $25 \%$. In addition, in 3,801 patients assessed for the efficacy analysis, benefits with the 4 week / 2 week regimen were observed, with a median survival time of 8.3 months and a 1 year survival rate of $33.3 \%$ (95\% confidence interval: 31.8 34.9) (11). The completion rate of the one-year schedule in the standard treatment schedule, 4-week method, did not reach $70 \%$ due to adverse reactions $(6,7)$. Compliance of the 4-week method was not satisfactory and an improvement in compliance remains an issue that must be addressed.

In our previous prospective randomized trial, the completion rate of the one-year schedule in the 3-week method (3-week administration followed by 1 -week rest) was $98 \%$ which was significantly greater than that in the 4-week method group. The 3-week method seemed to have excellent feasibility as adjuvant chemotherapy. In this study, we tried to evaluate antitumor effect of 3-week method for colorectal cancer as adjuvant chemotherapy with an oral anticancer drug, S-1. Five-year relapse-free survival rates in the 3-week method group was $89.6 \%$ which was significantly better than that in the 4-week method group, $74.2 \%$. The six-month completion rate in the 3-week method group was $100 \%$ which was significantly better than that in the 4-week method group, $85 \%$. The six-month completion rate in the 4-week method for gastric cancer was reported to be $83 \%$ which was not satisfactory. From the view of compliance, the 4-week method may not be an ideal treatment schedule.

According to the 2016 guideline, the recommend administration period is 6 months for the adjuvant chemotherapy after curative resection of colorectal cancer (10). As for the total accumulated dose of S-1 in six months schedule, that of the 3 -week method is $12,600 \mathrm{mg}$ ( $100 \mathrm{mg} \times 21$ days $\times 6$ courses) as compared to $11,200 \mathrm{mg}$ ( $100 \mathrm{mg} \times 28$ days $\times 4$ courses) for the 4-week method, if BSA is over $1.5 \mathrm{~m}^{2}$. The total accumulated dose of the 3-week method must be greater than that of the 4-week method if the dose per day is the same. Furthermore, there were no grade 3 or 4 adverse reactions in both laboratory and clinical findings in the 
3-week method group in this study.

2-week administration followed by 1 -week rest (2-week method) was reported to be a more feasible oral administration regimen for S-1 as adjuvant chemotherapy in gastric cancer as compared to the 4-week method (12). However, total accumulated dose of S-1 in the 2-week method is as many as that in the 4-week method in the same period of treatment.

S-1 with oxaliplatin (SOX), or Capecitabin with oxaliplatin (CapeOX) were not the standard treatment regimens during the term of this study (2008 -2012) in Japan because of medical cost and adverse reactions. Fluoropyrimidines with oxaliplatin is the standard treatment for patients with stage IIIc (TNM classification) colorectal cancer after curative resection in Japan now. S-1 alone is indicated for patients with stage IIla colorectal cancer as adjuvant chemotherapy.

\section{CONCLUSION}

In conclusion, the 3-week method of S-1 administration had good feasibility, high accumulated dose in six months and good relapse-free survival rates. The 3-week method with S-1 seems to be a standard adjuvant chemotherapy schedule for colorectal cancer. however, a large-scale prospective study is needed to clarify this issue.

\section{Limitations}

Some limitations of this study must be addressed. The study is a small cohort study which is based on the evaluation of retrospective data in a single institution, thus lacking randomization of patients.

\section{Conflict of Interest and Source of Funding}

All author has no conflict of interest. No financial support was obtained for this study.

\section{REFERENCES}

1. Carmichael J, Popiela T, Radstone D, Falk S, Borner M, Oza A, et al. Randomized comparative study of tegafur/uracil and oral leucovorin vs. parenteral fluorouracil and leucovorin in patients with previously untreated metastatic colorectal cancer. J Clin Oncol. 2002;20(17): 3617-27.

2. Akasu T, Moriya Y, Ohashi Y, Yoshida S, Sirao K, Kodaira S. National Surgical Adjuvant Study of Colorectal Cancer. Adjuvant chemotherapy with uracil-tegafur for pathological stage III rectal cancer after mesorectal excision with selective lateral pelvic lymphadenectomy: a multicenter randomized controlled trial. Jpn J Clin Oncol. 2006; 36(4):237-44. Epub 2006 May 4.

3. Shirasaka T, Nakano K, Takeuchi T, Satake H, Uchida J, Fujioka A, et al. Antitumor activity of $1 \mathrm{M}$ tegafur-0.4M 5-choloro-2,4-dihydroxypyridine-1M potassium oxonate (S-1) against human colon carcinoma orthotopically implanted into nude rats. Cancer Res. 1996;56(11):2602-6.

4. Sakata Y, Ohtsu A, Horikoshi N, Sugimachi K, Mitachi Y, Taguchi T. Late phase II study of novel oral fluoropyimidine anticancer drug S-1 (1M tegafur-0.4M gimestat-1 M otastat potassium) in advanced gastric cancer patients. Eur J Cancer. 1998;34(11):1715-20.

5. Koizumi W, Kurihara M, Nakano S, Hasegawa K. Phase II study of $\mathrm{S}-1$, a novel oral derivative of 5 -fluorouracil, in advanced gastric cancer. For the S-1 Cooperative Gastric Cancer Study Group. Oncology. 2000;58(3):191-7.

6. Kinoshita T, Nashimoto A, Yamamura Y, Okamura T, Sasako M, Sakamoto J, et al. Feasibility study of adjuvant chemotherapy with S-1 (TS-1; tegafur, gimeracil, oteracil potassium) for gastric cancer. Gastric Cancer. 2004;7(2):104-9.

7. Sakuramoto S, Sasako M, Yamaguchi T, Kinoshita T, Fujii M, Nashimoto A, et al.; ACTS-GC Group. Adjuvant chemotherapy for gastric cancer with S-1, an oral fluoropyrimidene. N Engl J Med. 2007;357(18):1810-20.

8. Kawahara H, Watanabe K, Ushigome T, Noaki R, Kobayashi S, Yanaga K. Feasibility study of adjuvant chemotherapy with S-1 (TS1; tegafur, gimeracil and oteracil potassium) for colorectal cancer. Hepatogastroenterology. 2012;59(113):134-7.

9. Ohtsu A, Baba H, Sakata Y, Mitachi Y, Horikoshi N, Sugimachi K, et al. Phase II study of S-1, a novel oral fluorophyrimidine derivative, in patients with metastatic colorectal carcinoma. S-1 Cooperative Colorectal Carcinoma Study Group. Br J Cancer. 2000; 83(2):141-5.

10. Watanabe T, Muro K, Ajioka $Y$, Hashiguchi $Y$, Ito $Y$, Saito $Y$, et al.; Japanese Society for Cancer of the Colon and Rectum. Japanese Society for Cancer of the Colon and Rectum (JSCCR) guidelines 2016 for the treatment of colorectal cancer. Int J Clin Oncol. 2018; 23(1):1-34. doi: 10.1007/s10147-017-1101-6. Epub 2017 Mar 27.

11. Nagashima F, Ohtsu A, Yoshida S, Ito K. Japanese nationwide post marketing survey of $S 1$ in patients with advanced gastric cancer. Gastric Cancer. 2005;8(1):6-11.

12. Yamatsuji $T$, Fujiwara $Y$, Matsumoto $H$, Hato $S$, Namikawa $T$, Hanazaki K, et al. Feasibility of oral administration of $S-1$ as adjuvant chemotherapy in gastric cancer: 4-week S-1 administration followed by 2-week rest vs. 2-week administration followed by 1-week rest. Mol Clin Oncol. 2015;3(3):527-532. Epub 2015 Feb 2. 